\title{
Evolução das conexões entre produção e consumo e seus impactos sobre as dinâmicas de um território: o caso de Mocajuba na Amazônia oriental - PA
}

\author{
Marc Piraux \\ Universidade Federal do Pará - Belém - Pará - Brasil \\ Pauline Hélène Cécile Marie Cuenin \\ Universidade Federal de Viçosa - Viçosa - Minas Gerais - Brasil
}

\section{Resumo}

Pelo alongamento das cadeias alimentares, o sistema alimentar global gera um distanciamento dos produtores agrícolas com os consumidores. Frente a essa conjuntura global, movimentos locais de resistência se destacam, propondo iniciativas de reaproximação entre agricultores e sociedade. Assim, o objetivo desse trabalho é analisar a evolução desses processos de desconexão e reconexão entre produção e consumo, assim como as reconfigurações territoriais desses movimentos nas últimas décadas no município de Mocajuba (PA) na Amazônia Oriental. Para atender ao objetivo, foi realizada uma análise dos fluxos de produtos agrícolas e alimentares entre o município e o exterior e dentro do município, complementada por uma análise da trajetória do território nas últimas décadas e dos projetos de desenvolvimento local atuais. Destacou-se um aumento relevante dos fluxos de produtos agroindustriais vindos de fora do município a partir dos anos 2000-2005, especificamente para as zonas rurais, possibilitado pelos programas sociais que elevaram a renda da população. Isso se traduz por uma dependência cada vez maior dessas zonas rurais em relação aos produtos agroalimentares "globalizados". Porém, observaram-se movimentos de valorização de produtos amazônicos de base alimentar tradicional como a farinha de mandioca e o açaí e, mais recentemente, iniciativas de reaproximação entre produtores e consumidores mocajubenses, tendendo a dinamizar as zonas rurais.

Palavras-chave: Globalização. Sistemas agroalimentares. Reconfigurações territoriais. Amazônia.

Evolution of the connections between production and consumption and its impacts on the dynamics of a territory: the case of Mocajuba in the eastern Amazon - PA

\section{Abstract}

With the elongation of the food chains, the global food system generates a distance between farmers and consumers. In front of this global conjuncture, local resistance movements are proposing initiatives of rapprochement between farmers and society. The 
objective of this work is to analyze the evolution of these processes of disconnection and reconnection between production and consumption, as well as the territorial reconfigurations provoked by these movements in the last decades in the municipality Mocajuba (PA) in the Eastern Amazon. To reach this goal, an analysis of the flows of agricultural and food products between the municipality and abroad and within the municipality was carried out, complemented by an analysis of the trajectory of the territory in the last decades and the current local development projects. There was a significant increase in the flow of agro-industrial products from outside the municipality from the years 2000-2005 and that have arrived reaching very strongly in the rural areas, allowed by the social programs that raised the income of the population. This is reflected in a growing dependency on these rural areas for new food products and in a marginalization of more isolated areas with less access to these products. However, there were movements of valorization of Amazonian food products, cassava flour and açaí, which allows rural areas not to be totally dependent or excluded from global dynamics. More recently, initiatives for rapprochement between producers and consumers in Mocajuba are being carried out, tending to boost rural areas.

Keywords: Globalization. Agro-food systems. Territorial re-configurations. Amazonia.

\section{Evolución de las conexiones entre producción y consumo y sus impactos sobre las dinámicas de un territorio: el caso de Mocajuba en la Amazonia oriental - PA}

\section{Resumen}

Por el alargamiento de las cadenas alimentarias, el sistema alimentario global genera un distanciamiento de los productores agrícolas con los consumidores. Frente a esta coyuntura global, movimientos locales de resistencia se destacan proponiendo iniciativas de acercamiento entre agricultores y sociedad. Así, el objetivo de este trabajo fue analizar la evolución de estos procesos de desconexión y reconexión entre producción y consumo, así como las reconfiguraciones territoriales provocadas por estos movimientos en las últimas décadas en el municipio Mocajuba (PA) en la Amazonia Oriental. Para atender al objetivo, se realizó un análisis de los flujos de productos agrícolas y alimenticios entre el municipio y el exterior y dentro del municipio, complementado por un análisis de la trayectoria del territorio en las últimas décadas y de los proyectos de desarrollo local actuales. Se destacó un aumento relevante de los flujos de productos agroindustriales provenientes de fuera del municipio a partir de los años 2000-2005 y llegando muy fuertemente en las zonas rurales, permitido por los programas sociales que elevaron la renta de la población. Esto se traduce en una dependencia cada vez mayor de estas zonas rurales en relación con los nuevos productos alimenticios, y por una marginación de las zonas más aisladas con menos acceso a estos productos. Sin embargo, se observaron movimientos de valorización de productos amazónicos de base alimentaria tradicional, la harina de mandioca y el açaí, lo que permite a las zonas rurales de no ser totalmente dependientes o excluidos de las dinámicas globales. Más recientemente, las iniciativas de acercamiento entre productores y los consumidores de Mocajuba se están haciendo, tendiendo a dinamizar las zonas rurales.

Palabras clave: Globalización. Sistemas agroalimentarios. Re-configuraciones territoriales. Amazonia.

\section{Introdução}

Desde o início da globalização do sistema agroalimentar, em meados da década dos anos 1980, a alimentação passa por um processo de desenraizamento com sua base ecológica. Assim, em um mundo cada vez mais globalizado, a 
sociedade está se desconectando tanto ao nível da produção dos produtos agrícolas como do consumo dos alimentos (SCHNEIDER e GAZOLLA, 2017). De fato, os "Impérios Alimentares", que se estruturam como um novo modo de ordenamento do sistema alimentar global, baseiam-se em um modelo de produção que explora a natureza e concentram a maioria dos mercados globais agrícolas e alimentares, provocando múltiplas desconexões (VAN DER PLOEG, 2008). Em particular, esse novo sistema alimentar global gera um distanciamento dos produtores com os consumidores pelo alongamento das cadeias alimentares. As cadeias alimentares longas invisibilizam os alimentos, sua identidade, sua procedência e quem está por trás de cada elo da cadeia alimentar, em particular, do processo produtivo agrícola, sendo uma característica do modo industrial de produção de alimentos (SCHNEIDER e GAZOLLA, 2017).

Frente a essa conjuntura global, movimentos locais de resistência se destacam, tais como os processos de manutenção e valorização de produções locais e iniciativas de reconexão dos produtores alimentares com os consumidores. Renting, Marsden e Banks (2017, p. 34) enfatizam o papel das cadeias curtas como "canais para a criação de novos vínculos entre agricultores e sociedade, produtores e consumidores" no âmbito do desenvolvimento rural. A agricultura familiar se encontra no coração deste processo (VAN DER PLOEG, 2008). O distanciamento e a reaproximação entre quem produz e quem consome repercutem sobre os territórios e suas dinâmicas, um território sendo considerado como um espaço apropriado e organizado (MOINE, 2006). A valorização dos produtos alimentares locais se enraíza em um espaço específico. O território apresenta assim uma forma material e simbólica (vivido e representado pelos atores do território) (RAFFESTIN, 1986).

No entanto, o território é também um espaço de poder entre atores com interesses diferentes, que tem capacidade ou não de regulação e de organização, para usar recursos naturais limitados (DI MEO, 2014). Idealmente, um sistema de governança, baseado em uma parceria entre sociedade civil e poder público, deveria implementar as bases de uma ação pública favorável a estas dinâmicas de reaproximação entre produção e consumo em um enfoque de desenvolvimento territorial (PECQUEUR, 2005). Este se constitui como um processo de mudança estrutural empreendido por uma sociedade organizada territorialmente, sustentada na potencialização dos capitais e recursos (materiais e imateriais). Ele tem em vistas à dinamização da economia e à melhoria da qualidade de vida da sua população (DalLabrida, 2010).

Esses movimentos de reaproximação entre produção e consumo dos alimentos apresentam dinâmicas especiais na Amazônia brasileira. De fato, ela é marcada por um grande patrimônio sociocultural que inclui produtos e culturas alimentares específicos, mas também, por ser uma zona de disputa de interesses econômicos e por dinâmicas globalizadas muito intensas que têm impactos socioespaciais (CASTRO, 2005). Essas dinâmicas são em particular ligadas às infraestruturas (os portos, por exemplo), ao desenvolvimento dos mercados e das dinâmicas empresariais internacionais, bem como aos quadros normativos postos em prática pelas autoridades públicas a partir de um referencial e de uma agenda política internacional (POLGE et al., 2015). Tais características peculiares fazem da Amazônia uma zona interessante de estudo das evoluções das configurações dos 
vínculos entre os agricultores familiares e os consumidores e seus impactos sobre o território, diretamente influenciados pela globalização.

Querendo se inscrever nesta temática, o objetivo deste artigo é analisar a evolução dos processos de desconexão e reconexão entre produção e consumo de alimentos, assim como as suas reconfigurações territoriais nas últimas décadas no município de Mocajuba (PA) na Amazônia Oriental. Esse município foi escolhido por vários critérios: seu tamanho pequeno (área), facilitando uma análise dos fluxos de recursos e materiais; sua grande diversidade socioecológica; suas diversas características tradicionais, em particular, a marcada presença da agricultura familiar. Mas, como no caso de muitos municípios amazônicos (PIRAUX et al., 2015), Mocajuba sofre de uma dificuldade na ação coletiva ao nível da agricultura familiar. Queremos mostrar que, neste município, frente a um processo de globalização homogeneizador dos padrões de consumo, existe um movimento de reconexão entre produção e consumo de alimentos ainda muito frágil, devido a fraqueza da ação coletiva e a dificuldade de construção de uma ação pública de qualidade necessárias para neutralizar as ações das grandes empresas agroalimentares.

\section{2 Área de estudo e procedimentos metodológicos}

O município de Mocajuba está situado a $200 \mathrm{~km}$ ao sul de Belém, capital do estado do Pará, na beira do rio Tocantins. A população do município é de 26.731 habitantes, incluindo 18.279 na área urbana e 8.452 na área rural (IBGE, 2010). Sua superfície é de $870,8 \mathrm{~km}^{2}$. Os produtos agrícolas produzidos no município provêm, na sua maioria, de uma agricultura familiar muito ativa no território ( $95 \%$ dos agricultores).

Para o estudo, o município de Mocajuba foi dividido em quatro áreas segundo o zoneamento realizado pelo GEDAF, o Grupo de Estudo sobre a Diversidade da Agricultura Familiar da Universidade Federal do Pará - UFPA (PIRAUX et al., 2017) (Figura 1):

- A área "Quilombola" da margem direita do rio, na qual a produção principal é a farinha de mandioca, sendo a zona mais isolada de Mocajuba (Zona 1);

- As "Ilhas" do rio onde moram os ribeirinhos, nas quais as atividades principais são a pesca e o extrativismo (açaí, borracha, cacau, murumuru', etc.) (Zona 2);

- A área da "Terra Firme" que inclui: uma área de bacia de produção da farinha de mandioca (Zona 4) e da pimenta do reino (o cultivo de renda) (Zona 5 excluindo o centro urbanizado) e uma área pequena quilombola com uma produção diversificada (Zona 3), mas também centrada na farinha de mandioca. Essas zonas foram agrupadas por proximidade geográfica e estrutural;

- O "Centro Urbano" de Mocajuba, essa área foi excluída da área da "Terra Firme" porque se associa a uma dinâmica urbana muito diferente da área rural. O principal setor de atividade é o comércio seguido pela indústria, educação e administração pública (IBGE, 2010). O mercado municipal e os

\footnotetext{
${ }^{1}$ Palmeira nativa da Amazônia cuja fruta está geralmente utilizada para fazer óleo/manteiga para usos na cosmética.
} 
vários outros mercados e supermercados da cidade são os principais espaços de aquisição de alimentos.

Figura 1. Zoneamento do município de Mocajuba

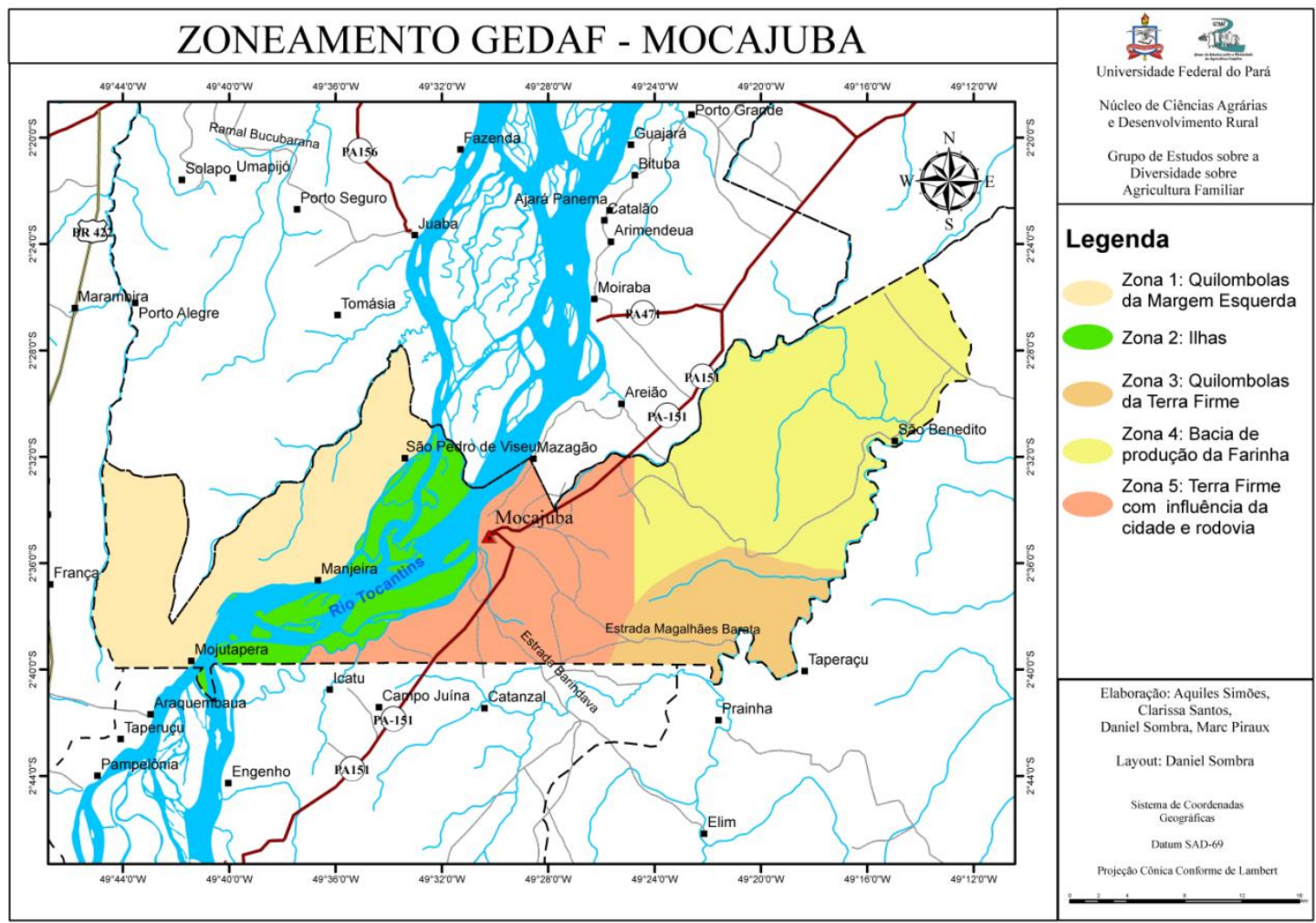

Fonte: Piraux et al., 2017.

Para alcançar o objetivo deste trabalho, foi realizada uma análise dos fluxos (REYNAUD, 1980) dos principais produtos agrícolas e alimentares entre as diferentes áreas do município e entre o município e o exterior, quer dizer, os fluxos entrando e saindo do município. De fato, os fluxos não aconteçam por acaso, eles traduzem os jogos de atores. Raffestin (1980), partindo de uma leitura relacional da organização do mundo, coloca os fluxos no centro da produção do espaço humano, isto é, da transformação do espaço em território onde "todas as relações são marcadas pelo poder" (RAFFESTIN, 1980, p.129). A maioria desses fluxos é impossível de descrever a partir das informações já existentes, cujos objetos são outros: uso da terra, vegetação, etc.

Para isso, foram recolhidos dados secundários a partir de diversos documentos disponíveis (trabalhos de pesquisa, informações de empresas, administrações públicas, etc.) e dados primários coletados através de entrevistas semiestruturadas e estruturadas feitas com vários atores do território (agricultores familiares, membros do Sindicato dos Trabalhadores e Trabalhadoras Rurais - STTR, Secretário da Agricultura, responsável e feirantes do mercado municipal, gerentes de supermercados, agentes de saúde, membros de diversas associações do município, a exemplo da Associação do Assentamento da Ilha da Conceição ou da Associação dos Descendentes Quilombolas, etc.). Os grandes tipos de fluxos agrícolas e alimentares e seus lugares de saída e de chegada, foram avaliados. Valorizando os saberes locais, uma análise da trajetória do território nas últimas 
décadas e dos projetos de desenvolvimento local atuais foi conduzida. Além disso, foi vivenciado o cotidiano de algumas famílias das diferentes áreas rurais e urbana (uma família por área) a fim de entender melhor as relações das pessoas com os alimentos e as dinâmicas presentes nessas áreas. A pesquisa de campo ocorreu em 2014 e foi complementada em 2016. Por fim, a validade das informações foi verificada pelo método de triangulação das fontes de informações. Uma restituição aos atores foi feita para validar os resultados e complementá-los.

\section{Das bases alimentares tradicionais ao aumento dos produtos agroindustriais e suas consequências}

Como cultura alimentar da população do estado do Pará, o açaí sempre foi a base alimentar das comunidades ribeirinhas de Mocajuba, tradicionalmente acompanhada de farinha de mandioca, peixe e camarão. O açaí, o peixe e o camarão, produtos que se encontram espontaneamente no ambiente dos rios amazônicos, eram tradicionalmente extraídos e autoconsumidos por essas famílias das "Ilhas" e uma pequena parte era voltada para a comercialização no "Centro Urbano" do município. A farinha de mandioca também era um produto alimentar tradicional em Mocajuba, produzida na "Terra Firme" e na área "Quilombola", autoconsumida pelas famílias dessas zonas rurais.

\subsection{Anos 80-90: mudanças no padrão de consumo alimentar}

No entanto, essa dinâmica tradicional do território mocajubense e do sistema alimentar local associado se transformaram por duas causas principais, nos anos 1980. A primeira foi a ativação de uma barragem hidroelétrica em 1985 construída no rio Tocantins a montante de Mocajuba. Isso teve impactos fortes sobre os recursos de peixes do rio e, consequentemente, sobre a base alimentar e a vida das populações ribeirinhas nas "Ilhas". A segunda está associada ao apogeu da cultura da pimenta do reino na "Terra Firme" nos anos 1970-1980, cultura que chegou no município nos anos 1960. Ela acompanhou a elevação do nível de vida dos produtores de pimenta e, sobretudo, das pessoas implicadas com o negócio (armazenamento e comércio) dessa cultura, a maioria residentes no "Centro Urbano" do município. Isso gerou mudanças nas necessidades e padrões de consumo por parte da população. No início dos anos 1990, chegaram produtos agroindustriais vindos de fora do município no mercado de Mocajuba, como o arroz, o feijão, a carne bovina e o frango.

Nos anos 1995, a crise da pimenta do reino (queda do preço no mercado internacional e doenças fúngicas como a fusariose da pimenta) teve como consequências o êxodo rural de uma parte dos agricultores da "Terra Firme" para fora do município ou para a sede do município, onde eles adotaram os padrões de consumo alimentar do centro. No mesmo período (1998), a chegada da energia elétrica também provocou modificações nos sistemas de consumo, com a compra de produtos manufaturados (televisão, geladeira etc.), associados ao aumento de consumo de produtos agroindustriais.

\footnotetext{
${ }^{2}$ Colocamos entre aspas os nomes das zonas do zoneamento apresentadas na área de estudo.
} 


\subsection{Anos 2000: programas sociais e homogeneização dos padrões culturais e alimentares}

No entanto, foi durante a década dos anos 2000 que se observou um crescimento relevante dos fluxos agroindustriais vindos principalmente da região de Belém e Castanhal e da esfera nacional. De fato, uma série de programas sociais foi desenvolvida pelo governo federal, com destaque para o programa Bolsa Família iniciado em 2003, que permitiu um aumento da renda das populações principalmente rurais e seu acesso a novos produtos de consumo. Nesse processo, é importante ressaltar o decreto $\mathrm{n}^{0} 6.040 / 2007$ que trata do reconhecimento e do desenvolvimento das populações tradicionais. Esse decreto permitiu reconhecer as comunidades quilombolas (na "Terra Firme" processo iniciado em 2008 com recepção do título do território quilombola em 2013) e tornar essas populações e seus territórios prioritários para a aplicação dos programas nacionais como o acesso à eletricidade, Bolsa Família etc. A política do governo federal da reforma agrária aplicada no estado do Pará permitiu também a criação de um assentamento agroextrativista nas "Ilhas" do município, em 2008, a partir do qual cada família recebeu uma quantidade de dinheiro para adquirir bens de primeira necessidade.

Esses programas nacionais associados, entre outros, ao Seguro Defeso 3 de pesca e à aposentadoria rural, permitiram melhorar as condições de vida dos habitantes, principalmente nas zonas rurais e das comunidades tradicionais, e facilitar suas condições de acesso aos bens de consumo, quer seja produtos agroindustriais ou manufaturados. Esse acesso foi fortalecido também pelas melhorias das infraestruturas e das condições de transporte (barco a motor, motocicleta) entre as zonas rurais e o centro urbano, e entre o município e o exterior.

O acesso facilitado e a abundância desses produtos agroindustriais no mercado mocajubense, visto o desenvolvimento dos supermercados, trouxeram profundas mudanças nos modos de consumo alimentares. Voltando-se cada vez mais para o consumo de produtos agroindustriais, as populações de Mocajuba reduziram muito o consumo de produtos do seu ambiente próximo, desvalorizando cada vez mais os produtos locais. Um morador das "Ilhas" de 76 anos confirma que há 30 anos: "comíamos peixe, açaí e farinha todo dia, feijão e arroz era uma vez por ano; hoje, comemos todo dia". Foi relatado também, que nesse contexto, alguns deixaram de produzir farinha de mandioca em algumas áreas da "Terra Firme" e da área "Quilombola".

Outro fator relevante nas mudanças dos padrões alimentares está ligado à importância das informações vindas do nível nacional e internacional, característica da globalização hegemônica. Observou-se em Mocajuba uma onipresença da televisão em todas as zonas do território e anúncios constantes de carros de som no "Centro Urbano" do município. Essas informações difundem imagens e padrões culturais diferentes e propagandas que promovem o consumo

\footnotetext{
3 O seguro defeso é um benefício concedido pelo Governo Federal ao pescador artesanal que obtém renda exclusivamente da pesca. Portanto, é uma espécie de “seguro desemprego" do pescador, que em alguns períodos do ano fica impedido de pescar, para assegurar a preservação dos peixes.
} 
de produtos agroindustriais que, obviamente, não vêm acompanhadas de informações sobre suas características, seu uso e os possíveis riscos à saúde.

Progressivamente, houve uma homogeneização dos padrões alimentares entre o "Centro Urbano" do município e as diferentes zonas rurais do território mocajubense. Mas ela não atingiu todas as zonas do território mocajubense. Assim, e de uma maneira um pouco paradoxal, a marginalização da zona "Quilombola", consequência da sua grande distância da sede do município e do restrito acesso aos seus serviços, inclusive à televisão, implicou uma melhor autonomia alimentar.

Essa estandardização da base alimentar é característica do sistema alimentar global, o que gera a redução das diferenças culturais e regionais na comida e nas dietas alimentares (GLIESSMAN, 2015). De uma maneira geral, a ampliação da quantidade desses produtos agroindustriais cria uma dependência cada vez maior das zonas rurais e das suas populações à esses produtos alimentares. Ela provoca um desenraizamento das populações rurais com sua base natural, sua cultura alimentar e seu ambiente local, inserindo-as na lógica do sistema agroalimentar global dominante (SCHNEIDER e GAZOLLA, 2017), fonte de um processo de desterritorialização (THERY, 2008). Mas, teve também outros impactos sobre a saúde e o meio ambiente.

De fato, percebeu-se nas zonas rurais de Mocajuba uma crescente valorização de produtos alimentares como os refrigerantes ou biscoitos industriais, poucos nutritivos e com altos riscos à saúde (SCHNEIDER e GAZOLLA, 2017). O alto consumo desses produtos pelas crianças gera muitos problemas dentários e de obesidade, que se agravam pelas dificuldades de acesso aos centros de saúde. Esses problemas sanitários foram confirmados pelos serviços de saúde do município.

Outra consequência negativa dessa mudança no padrão de consumo se refere à alta quantidade de lixo no meio ambiente, resultante do volume das embalagens geralmente plásticas dos produtos agroindustriais e da gestão fraca da coleta de lixos nas zonas rurais. As entrevistas e a vivência nas famílias confirmaram que a população continua jogando essas embalagens no meio ambiente como se fosse qualquer resíduo orgânico sem ter consciência dos danos causados ao meio ambiente.

\section{A valorização de produtos amazônicos de base alimentar: entre estratégias de resistência, ameaças e riscos}

Nesses últimos anos (anos 2010-2015) foi possível observar que apesar da integração da maioria das áreas rurais do município ao sistema alimentar global, alguns produtos amazônicos tradicionais de base alimentar se destacaram por serem objeto de valorização por diversos atores locais. Essas novas dinâmicas correspondem a estratégias de reativação de recursos locais específicos (PECQUEUR, 2005).

\subsection{A produção de farinha de mandioca de qualidade: uma estratégia de resistência}

O cultivo da mandioca para transformação em farinha ainda é uma das principais atividades agrícolas de uma parte da área da "Terra Firme" e da área "Quilombola", sendo produzida para o autoconsumo e fonte de renda. Sousa e 
Piraux (2015) enfatizaram que a venda de farinha de mandioca das comunidades "Quilombolas", as que estão marginalizadas, ganhou destaque nesses últimos anos. Os consumidores do "Centro Urbano" ou até de municípios vizinhos, reconhecem a alta qualidade do produto e compram-no. Outras comunidades, como a de Baratinha situada na "Terra Firme", buscaram também um melhoramento da qualidade do processo de transformação da mandioca. As adaptações e mudanças de práticas associadas a esse processo resultaram de uma série de troca de informação e de experimentação dos próprios agricultores (SOUSA e PIRAUX, 2015). O objetivo era também desenvolver um nicho de mercado no "Centro Urbano" de Mocajuba e assim resolver as dificuldades de comercialização da farinha, o que foi feito de fato. A busca da qualidade se torna uma nova norma para as comunidades rurais.

Esses são exemplos de estratégias de resistência dos camponeses frente às forças do sistema alimentar global. De fato, segundo Van Der Ploeg $(2008,2009)$, essa resistência acontece em vários níveis e sob várias formas, construindo uma multiplicidade de respostas que reconectam as pessoas, as atividades e os projetos. Elas permitem estabelecer ou manter novas ligações com o consumidor, dar visibilidade do produto, trazer uma identidade própria e aumentar a autonomia dos produtores, contribuindo assim com um processo de reterritorialização (VAN DER PLOEG, 2008). Essas estratégias de resistência e de reaproximação com os consumidores locais são importantes para criar um novo dinamismo nas zonas rurais. No entanto, é importante também ressaltar as ameaças externas a esses processos.

\subsection{A ameaça da agricultura industrial}

Primeiramente, ameaças foram observadas pela chegada na "Terra Firme" de grandes proprietários que investem e se apropriam de grandes áreas, para desenvolver o cultivo da pimenta do reino, do açaí irrigado ou a criação de gado, gerando entre outros, concorrência no uso da água com os agricultores familiares, fontes de alguns conflitos. Esta apropriação e degradação dos recursos naturais é, de maneira geral, um tipo de ameaça externa à agricultura familiar ressaltada por Van Der Ploeg (2014). Por exemplo, na "Terra Firme" de Mocajuba, foi relatado um caso conflituoso entre um grande proprietário e uma comunidade quilombola vizinha. Moradores dessa comunidade observaram uma diminuição da quantidade de água do rio devido às práticas de irrigação no cultivo do açaí. Esses conflitos sociais influenciam diretamente a produção dos agricultores familiares. Constatouse também dificuldades de acesso físico a terras de alguns agricultores familiares pela apropriação de grande quantidade de terras por grandes produtores rurais.

Além disso, a implementação de cultivos comerciais tipo "commodities" de destino nacional e internacional pode competir com os cultivos de base alimentar tradicional e/ou desvalorizar os conhecimentos tradicionais dos agricultores familiares. De fato, os sistemas de produção desses cultivos se baseiam nas práticas e padrões estandardizados do regime sociotécnico da agricultura industrial orientado pelos valores do mercado e princípios da ciência moderna: lavoura intensiva, aplicação de fertilizantes sintéticos, irrigação, controle químico das pragas pelo uso de agrotóxicos e manipulação do genoma vegetal (GLIESSMAN, 
2015). São sistemas de produção cada vez mais especializados e artificializados, que provocam várias desconexões (VAN DER PLOEG, 1992; VAN DER PLOEG et al., 2004). Em particular, destaca-se um distanciamento com a natureza e um rompimento com a dinâmica de manutenção dos equilíbrios ecológicos e com as práticas e conhecimentos locais (CAPORAL e COSTABEBER, 2007).

$\mathrm{Na}$ "Terra Firme" de Mocajuba, os cultivos da pimenta do reino e, sobretudo, do dendê, são os dois principais cultivos baseados nesses princípios. O projeto BBB (Belém Bioenergia Brasil, formado pela Petrobras e a empresa portuguesa Galp) iniciou em 2013 o cultivo de dendê nas propriedades dos agricultores familiares do município. O objetivo inicial era a produção de biodiesel a partir de um estímulo das políticas públicas (Pronaf Eco-dendê). A implementação desse projeto foi acompanhado da implementação de regras de gestão e do uso de pacotes tecnológicos impostos pelas empresas. A saída completa do BBB em 2016, por razão de uma falta de rentabilidade e do difícil acesso ao município (presença de uma balsa em um rio na estrada principal para Belém), deixou os agricultores familiares comprometidos com a empresa, sem apoio e com um futuro incerto. Alguns agricultores diminuíram também a produção de mandioca.

Gliessman (2015) já chamava atenção para o fato que, diante da pressão do sistema alimentar global para plantar cada vez mais cultivos comerciais, o consumo de produtos locais e a venda nos mercados locais são reduzidos. Os sistemas agrícolas associados a esses cultivos geram a desvalorização dos conhecimentos tradicionais dos agricultores familiares, que no entanto são importantes para a autonomia das famílias agrícolas e para a construção de sistemas alimentares alternativos.

Outra ameaça externa sobre os sistemas de produção da agricultura familiar e sobre as potencialidades de iniciativas de valorização de produtos tradicionais está relacionada à volatilidade dos mercados agrícolas e à flutuação dos preços de venda dos produtos (VAN DER PLOEG, 2014). Quando os preços dos cultivos comerciais estão subindo, os agricultores são incentivados a deixar de cultivar produtos alimentares básicos. Por exemplo, em Mocajuba, constatou-se uma retomada da cultura da pimenta do reino nesses últimos anos devido ao aumento do seu preço de venda, o que repercute sobre as áreas de produção de mandioca, cujo cultivo é considerado como mais penoso.

\subsection{0 desenvolvimento do açaí nas "Ilhas": entre estratégia de resistência e riscos}

No processo de valorização dos produtos de base alimentar amazônica, além da farinha de mandioca, o desenvolvimento do cultivo do açaí é outro fenômeno interessante a mencionar no território mocajubense. O cultivo de açaí de várzea é tradicional nas "Ilhas" e é representativo do agroextrativismo e da cultura ribeirinha nessa área. O cultivo de açaí aumentou bastante nesses últimos anos em resposta ao crescimento da demanda regional, nacional e internacional. Nesses dez últimos anos, foi observado um fluxo de venda crescente das "Ilhas" para o "Centro Urbano" de Mocajuba. Lá, ele é consumido diretamente ou vendido por meio de atravessadores para o mercado regional. Em Mocajuba, a produção fica no domínio dos ribeirinhos e não é imposta por agentes externos. Essa valorização dos recursos 
locais permite dinamizar a área das "Ilhas" do município, sendo essa atividade uma fonte de renda muito importante.

No entanto, vários riscos estão associados a esse processo. Primeiro, a fim de responder a uma demanda crescente do mercado nacional ou internacional, o açaí tende a entrar em cadeias alimentares longas, nas quais o padrão de produção evolui como uma "commodity": estandardização das práticas (monocultura e irrigação), busca da rentabilidade financeira, produtivismo e no final, perda da identidade do produto ao longo da cadeia. Além disso, Homma et al. (2006) demonstraram que a expansão do consumo da polpa de açaí promove a exclusão social de consumidores com menor poder aquisitivo que eram tradicionalmente os principais consumidores. É o caso de alguns agricultores ribeirinhos mocajubenses que estão vendendo a sua produção de açaí para comprar produtos agroindustriais.

$\mathrm{Na}$ "Terra Firme" de Mocajuba, já se pode observar o florescimento de áreas de cultivo de açaí irrigado, desconectando essa planta do seu ambiente e manejo tradicional. Com a demanda crescente e os programas do governo do estado do Pará para aumentar a produção de açaí, a implementação de novas áreas de açaí irrigado na "Terra Firme" deve aumentar, podendo concorrer com os outros produtos de base alimentar das famílias rurais.

Resumindo, a valorização dos produtos tradicionais, quer seja o açaí ou a mandioca, são importantes para reaproximar o agricultor e o consumidor com seu ambiente e sua cultura local, dinamizando assim as zonas rurais produtoras. No entanto, muitos cuidados são necessários para não cair na lógica dos "Impérios Alimentares", que tendem a alongar as cadeias de abastecimento e eliminar os saberes, as memórias e a identidade dos produtos alimentares.

Frente à riqueza dos recursos locais das "Ilhas", outros produtos do agroextrativismo poderiam ser valorizados pelos ribeirinhos, por meio do reconhecimento da origem e da qualidade dos produtos alimentares, a exemplo do caso do cacau. Os processos de valorização do cacau ainda enfrentam várias dificuldades. Em 2013, o comprador de cacau do município iniciou um processo para valorizar esse produto através de uma certificação orgânica em conjunto com alguns agricultores, considerando uma demanda de uma cooperativa de Castanhal. A tentativa foi um fracasso frente às dificuldades burocráticas do processo encontradas pelos agricultores, a dificuldade da ação coletiva e a carência de formação de lideranças locais, típica desta zona (PIRAUX et al., 2015). Pois, os lideres locais têm um papel importante como agentes de mudanças (ROEPE e WISKERKE, 2004). Eles permitem impulsionar mudanças por mobilizar e iniciar a ação coletiva e, assim, criar estratégias inovadoras ao nível local.

\section{Iniciativas de reconexão da produção local com os consumidores mocajubenses}

Em Mocajuba, observou-se outras iniciativas que vão além da valorização de produtos amazônicos de base alimentar tradicional e que permitem reaproximar produtores e consumidores do município. Destacam-se fluxos de produtos alimentares locais entre as diferentes áreas de Mocajuba. Esses fluxos de poucas intensidades (em volume e valor monetário) correspondem a iniciativas feitas com a finalidade de valorizar e aumentar a produção local para abastecer a demanda também local. Uma série de iniciativas podem ser destacadas. 
A partir do ano 2016, salienta-se uma dinamização na implementação do Programa Nacional de Alimentação Escolar (PNAE), programa altamente interessante para fortalecer a produção familiar local (Resque et al., 2019), conduzindo assim a redução da dependência aos alimentos externos. Por meio do PNAE, a Secretaria da Agricultura do município tentou iniciar projetos de criação de peixes e de distribuição de sementes de feijão com os agricultores da "Terra Firme" para promover a produção local. Outros produtos locais como a mandioca e seus derivados, o maracujá, o jerimum, por exemplo, integraram o programa. Além disso, o PNAE, por apoiar a comercialização da galinha caipira, estimulou a criação de galinhas caipiras, que se desenvolveu no município por inciativas de alguns agricultores. Mesmo que as quantidades vendidas no mercado sejam mínimas, em comparação com o volume de frangos industriais, essa experiência é um exemplo concreto de iniciativas locais, com potencialidade de crescimento no município. Nessa mesma perspectiva de reaproximar produtores agrícolas e consumidores mocajubenses, o Sindicato dos Trabalhadores e Trabalhadoras Rurais (STTR) começou a promover os produtos locais (legumes e frutas) com a realização de feiras agroecológicas ${ }^{4}$ em 2016.

No entanto, essas iniciativas de reconexão enfrentam muitas dificuldades. Primeiramente, a segunda edição da feira agroecológica fracassou por uma razão que o STTR levantou: tanto para os agricultores quanto para os consumidores faltam informações e conhecimentos quanto à importância de valorizar os produtos locais. A mobilização dos produtores e consumidores foi difícil. Segundo um membro do STTR, os agricultores não estavam percebendo que eles tinham produtos que poderiam vender. Essa mesma liderança sindical observou que os consumidores da feira eram aqueles com nível escolar mais alto (médicos, professores etc.), os quais consideram esses produtos de maior qualidade. Os outros consumidores preferiam comprar frutas a varejo, mesmo com preços iguais aos dos produtos da feira.

Como salienta Gliessman (2015), os sistemas alimentares globais, ao desconectar os processos de produção da distribuição, isolam os consumidores das informações necessárias para ter maiores conhecimentos sobre a importância das escolhas alimentares. Por parte dos produtores, a concentração de poder dos "Impérios Alimentares" faz com que os produtos da agricultura familiar sejam geralmente desprezados, considerados fora dos padrões do sistema alimentar global (VAN DER PLOEG, 2009). Muitos consumidores e jovens entrevistados destacam este fato.

Com o objetivo de informar, sensibilizar e emancipar mais agricultores e consumidores sobre o assunto, o STTR em parceria com a UFPA e a Federação de Órgãos para Assistência Social e Educacional (FASE) ${ }^{5}$, começaram a organizar

\footnotetext{
${ }^{4}$ Agroecologia se refere a ações que promovam mudanças nas dimensões ecológica, econômica e social do sistema agroalimentar para atingir um sistema mais sustentável e justo (GLIESSMAN, 2018). $\mathrm{Na}$ feira agroecológica, encontram-se produtos que se originam de sistemas de produção baseados no conhecimento da população local, na diversidade biológica e cultural do local de produção com mínimo de impacto ao meio ambiente mas não necessariamente com certificação orgânica que está regida por regras de produção específicas.

${ }^{5}$ A FASE é uma organização não governamental, fundada em 1961, que tem por missão de contribuir para a construção de uma sociedade democrática e atuante em favor de alternativas ao modelo de
} 
oficinas e seminários sobre diversos temas ligados à agroecologia. Iniciou-se com oficinas com grupos de mulheres. A FASE junto com a rede da Associação Paraense de Apoio às Comunidades Carentes (APACC), que tem sua sede no município vizinho, organizam projetos e ações sobre agroecologia e economia solidária na região como, por exemplo, o Fórum da Economia Solidária e projetos na área "Quilombola" de Mocajuba. Assim, o reforço desses temas em Mocajuba e o início da estruturação de um movimento agroecológico dentro das redes agroecológicas regionais é um sinal promissor para desenvolver iniciativas de reconexão da produção local com os consumidores de Mocajuba.

Mas, de maneira geral, essas iniciativas enfrentam também muitas dificuldades. A primeira dificuldade está ligada aos preços muito baixos dos produtos agroindustriais que entram em competição desigual com os produtos da agricultura familiar. De fato, no contexto do monopólio de poder dos "Impérios Alimentares", está muito mais difícil, tanto para os agricultores quanto para os consumidores, sair dos circuitos controlados por eles (VAN DER PLOEG, 2009). Assim, para guardar o monopólio sobre o mercado, uma estratégia possível das grandes empresas ligadas às redes de supermercados, é fazer cair os preços dos seus produtos para serem ainda mais competitivos frente aos produtos da agricultura familiar. Em Mocajuba, esse fenômeno aconteceu após a introdução no mercado local de galinhas caipiras criadas por agricultores familiares, projeto iniciado por um dos antigos secretários da agricultura e que fracassou devido à queda dos preços dos frangos industriais. O que mostra a dificuldade de criar um sistema de governança territorial que implica todos os atores locais, inclusive os privados.

Essa dificuldade está diretamente associada ao contexto político local. A existência de processos judiciários ligados a problemas de corrupção que envolvem a prefeitura, provocou uma forte instabilidade política. No momento da pesquisa, o prefeito foi de fato, obrigado a deixar o cargo após dois anos de batalha jurídica, retornando ao cargo em um momento posterior e deixando-o novamente em um curto período de tempo depois. Isso explica a desorganização dos serviços municipais e o não funcionamento do Conselho Municipal de Desenvolvimento Rural Sustentável (CMDRS), principal instância de governança dos municípios para a área rural. Isso fragilizou também a implementação do PNAE nos anos 2010-2015 até as recentes iniciativas destacadas anteriormente.

\section{Considerações finais}

No município de Mocajuba, a globalização alimentar se traduziu, a partir dos anos 2000-2005, na ampliação da quantidade de produtos agroindustriais oferecidos no mercado local. Os programas sociais, cuja população foi beneficiada, facilitaram o acesso a esses produtos. A chegada intensa desses produtos de cadeia longa nas zonas rurais do município gerou processos de desvalorização dos produtos locais e de elementos a eles vinculados, a exemplo da identidade cultural e do saber-fazer. A globalização reconfigurou também outras dinâmicas locais, 
aumentando os fluxos para fora do município de produtos locais como o açaí, alimento de base das populações ribeirinhas. Esses processos provocaram um distanciamento das populações rurais com os produtos alimentares locais tradicionais e uma mudança do padrão de consumo alimentar, consequência da circulação intensificada de produtos agroindustriais e de informações que veiculam um novo modelo cultural alimentar que parece negar a territorialidade. A homogeneização desse padrão alimentar entre as diferentes zonas do município se tornou uma realidade. Podemos falar de um processo de desterritorialização (THERY, 2008).

Em contraposição a esse processo hegemônico imposto pelo sistema alimentar global, estratégias de resistência de agricultores familiares se desenvolveram. Elas tentam revalorizar os produtos tradicionais locais e reaproximar os produtores locais com os consumidores de Mocajuba. Fluxos novos aparecem. A qualidade dos produtos se torna uma nova norma, abrangendo os processos de produção e transformação, como no caso da farinha de mandioca e a qualidade sanitária dos alimentos no quadro dos produtos agroecológicos e caipiras. No entanto, identificamos ameaças e riscos a este processo de reterritorialização, impostos pelo regime alimentar hegemônico que tendem a diminuir e até bloquear a criação de experiências inovadoras (VAN DER PLOEG et al., 2004). Essas ameaças combinadas a um contexto político local não favorável, limitaram o impacto dessas iniciativas.

As iniciativas inovadoras identificadas a campo, mesmo que ainda de pequeno alcance, frágeis e sujeitas a muitas ameaças, tendem a reconfigurar as cadeias de abastecimento alimentar. Elas criam novos vínculos entre agricultores e sociedade e aproximam uma parcela de consumidores dos alimentos, de suas características e de sua localidade. Isso foi possível através da capacidade de resistência e de articulação de vários atores locais, que promoveram novos tipos de projetos de desenvolvimento rural baseados na valorização dos produtos locais. Esta afirmação converge com as ideias de Goodman (2017) e Renting, Marsden e Banks (2017) que demonstram que a reconfiguração das cadeias de abastecimento é subjacente à emergência de novas práticas de desenvolvimento rural. No entanto, esses projetos atingem principalmente a zona rural da "Terra Firme" deixando à margem a zona "Quilombola" que sempre foi mais isolada de vários processos.

Lidar com a diversidade das zonas rurais se torna um desafio importante. Vale ressaltar assim a importância de considerar as especificidades ecológicas e culturais de cada área do município na construção de estratégias de reconexão entre produção e consumo de alimentos saudáveis e sustentáveis.

Para dinamizar a emergência de novas estratégias, políticas públicas específicas são necessárias, como as ligadas à formação e ao acompanhamento ou aos programas de compra institucional de alimentos. Mas para melhorar a eficácia dessas políticas públicas, elas têm que se combinar ao fortalecimento de uma ação coletiva e de uma capacidade organizacional, dando origem a uma ação pública de qualidade. Vimos em nosso caso que a governança territorial, ou seja, a capacidade de uma sociedade organizada territorialmente de gerenciar e controlar os assuntos públicos era muito fraca. Mas ela seria necessária para melhorar a regulação da ação de grandes empresas e do acesso aos recursos (terra, água), cujo uso é cada vez mais tenso no contexto da globalização. Essa necessária articulação entre 
territórios e funcionamento das cadeias produtivas se torna um importante desafio de pesquisa e de desenvolvimento.

De maneira geral, as perspectivas multinível e multiator, típicas do desenvolvimento territorial, se tornam essenciais para a construção de novas experiências locais e sistemas alimentares alternativos. Nesse sentido, o reforço na construção da rede agroecológica territorial em formação, que inclui vários tipos de atores, é relevante para repensar os sistemas agroalimentares, os modelos clássicos de desenvolvimento territorial e estimular múltiplas estratégias inovadoras revalorizando práticas locais dos agricultores e povos tradicionais, especificamente no que tange ao agroextrativismo.

Esses processos deveriam ser promovidos a partir de quadros políticos e normativos locais, regionais e nacionais, no sentido contrário da desconstrução atual de muitas políticas públicas de fortalecimento da agricultura familiar.

\section{REFERÊNCIAS}

CAPORAL, F. R.; COSTABEBER, J. A. Agroecologia: Conceitos e Princípios para a Construção de Estilos de Agriculturas Sustentáveis. In: CAPORAL, F. R. (Orgs.). Extensão Rural e Agroecologia: temas sobre um novo desenvolvimento rural, necessário e possível. Brasilia: MDA, 2007, p. 225-240.

CASTRO, E. Dinâmica socioeconômica e desmatamento na Amazônia, Novos Cadernos NAEA, v. 8, n. 2, p. 5-39, dez. 2005.

DALLABRIDA, V. R. Desenvolvimento e Governança territorial: um ensaio preliminar sobre a necessidade da regulação no processo de gestão do desenvolvimento. REDES, v. 15, n. 3, p. 165-186, 2010.

DI MEO, G. Introduction à la géographie sociale. Paris: Arnaud Collin, 2014.

FASE. Missão e estratégia. 2019. Disponível em: <https://fase.org.br/pt/quemsomos/missao-e-estrategia/>. Acesso em: 10 de junho de 2019.

GLIESSMAN, S. R. Agroecology : The Ecology of Sustainable Food Systems. Taylor \& Francis Group, 2015.

GLIESSMAN, S. Agroecology and Sustainable Food Systems. Agroecology and Sustainable Food Systems, v. 42, n. 6, p. 599-600, 2018. Disponível em: <https://doi.org/10.1080/21683565.2018.1432329>. Acesso em: 10 de junho de 2019.

GOODMAN, D. Espaço e lugar nas redes alimentares alternativas : conectando produção e consumo. In: SCHNEIDER, S.; GAZOLLA, M. (Orgs.). Cadeias curtas e redes agroalimentares alternativas : negócios e mercados da agricultura familiar. Porto Alegre: Editora da UFRGS, 2017, p. 59-82. 
HOMMA, A. K. O., NOGUEIRA, O. L., MENEZES, A. J. E. A., CARVALHO, J. E. U., NICOLI, C. M. L., MATOS, G. B. Açaí : novos desafios e tendências. Amazônia: ciência e desenvolviemento, v. 1, n. 2, p. 7-23, 2006.

IBGE. Mocajuba. 2010. Disponível em:

<https://cidades.ibge.gov.br/brasil/pa/mocajuba/panorama>. Acesso em: 9 de novembro de 2017.

MOINE, A. Le territoire comme un système complexe. L'espace géographique, v. 2, n. 35, p. 115-132, 2006.

PECQUEUR, B. Desenvolvimento territorial: uma nova abordagem dos processos de desenvolvimento para as economias do Sul. Raízes, v. 24, n. 1 e 2, p. 10-22, 2005.

Piraux M., Cialdella N., Poccard-Chapuis R., Assis W. O futuro incerto da agricultura familiar na amazônia brasileira: um desafio para territórios e políticas públicas. In:

MIRANDA C., GUIMARÃES I. (Orgs.). Agricultura familiar, ruralidade, território e política pública. (Serie DRS vol 23). Brasília : IICA, 2015, p. 85-92.

Piraux M., Sombra Soares D., Simoes A. A diversidade socioespacial do território baixo tocantins e impactos na agricultura familiar. In: SIMÕES A., BENASSULY M. (Orgs.). Na várzea e na terra firme: transformações socioambientais e reinvenções camponesas. Belém : Universidade Federal do Pará, 2017, p. 77-114.

Polge, E., Poccard-Chapuis, R., Piraux, M., Territoires émergents d'Amazonie: analyse comparée des dynamiques territoriales dans le Baixo Amazonas et le Nordeste Paraense. Confins, v. 24, 2015. Disponível em: < http://confins.revues.org/10290>. Acesso em: 16 de fevereiro de 2019.

RAFFESTIN, C. Ecogénèse territoriale et territorialité. In: AURIAC, F.; BRUNET, R. (Orgs.). Espaces, jeux et enjeux. Paris: Fayard, 1986, p. 175-185.

RAFFESTIN, C. Pour une géographie du pouvoir. Paris: Libraires techniques, 1980.

RENTING, H.; MARSDEN, T.; BANKS, J. Compreendendo as redes alimentares alternativas : o papel de cadeias curtas de abastecimento de alimentos no desenvolvimento rural. In: SCHNEIDER, S.; GAZOLLA, M. (Orgs.). Cadeias curtas e redes agroalimentares alternativas : negócios e mercados da agricultura familiar. Porto Alegre: Editora da UFRGS, 2017, p. 27-52.

Resque A.G.L., Coudel E., Piketty M.G., Cialdella N., Sá T., Piraux M., Assis W., Le Page C. 2019. Agrobiodiversity and public food procurement programs in Brazil: Influence of local stakeholders in configuring green mediated markets. Sustainability, v. 11, n. 5, 2019. Disponível em: <https://doi.org/10.3390/su11051425>. Acesso em: 26 de junho de 2019. 
SCHNEIDER, S.; GAZOLLA, M. Cadeias curtas e redes agroalimentares alternativas. In: SCHNEIDER, S.; GAZOLLA, M. (Orgs.). Cadeias curtas e redes agroalimentares alternativas : negócios e mercados da agricultura familiar. Porto Alegre: Editora da UFRGS, 2017, p. 9-24.

SMITH, C.; BRAGDON, S. H. Small-scale farmer innovation. Geneva: Quaker United Nations Office, 2015.

SOUSA, F. F. De; PIRAUX, M. A construção social da qualidade da farinha de mandioca em comunidades rurais na Amazônia paraense. Novos Cadernos NAEA, v. 18, n. 3, p. 199-222, 2015.

THERY H. Mondialisation, déterritorialisation, reterritorialisation. Bulletin de I'Association de Géographes Français, v. 85, n. 3, p. 324-331, 2008.

VAN DER PLOEG, J. D. El processo de trabajo agrícola y la mercantilización. In: GUZMAN, E. S. (Orgs.). Ecología, Campesinado e Historia. Madrid: Ediciones, 1992, p. 163-195.

VAN DER PLOEG, J. D. BOUMA, J., RIP, A., RIJKENBERG, F. H. J., VENTURA, F., WISKERKE, J. S. C. On regimes, novelties, niches and co-production. In: WISKERKE, J. S. C.; PLOEG, J. (Orgs.). Seeds of Transition. Essays on novelty production, niches and regimes in agriculture, 2004.

VAN DER PLOEG, J. D. Camponeses e Impérios Alimentares. Porto Alegre: UFRGS, 2008.

AN DER PLOEG, J. D. Sete teses sobre a agricultura camponesa. Revistas

Agriculturas: Experiências em Agroecologia, n. Especial, p. 17-32, 2009.

VAN DER PLOEG, J. D. Cadernos de dabate : Dez qualidades da agricultura familiar. Agriculturas, n. 1, p. 1-16, 2014.

Marc Piraux. Doutor em Agro-economia pela Faculté des sciences agronomiques de Gembloux (FUSAGX), Bélgica. Pesquisador do Centre de coopération International en Recherche Agronomique pour le Développement (CIRAD). Professor da Universidade Federal do Pará (UFPA).marc.piraux@cirad.fr

Pauline Hélène Cécile Marie Cuenin. Mestre em Agronomia e Meio-Ambiente no Institut National Supérieur des Sciences Agromiques. Mestranda em Extensão Rural na Universidade Federal de Viçosa (UFV).pauline.cuenin@ufv.br 